\title{
A closer look at site index - biogeoclimatic site series correlations: Douglas-fir in the Coastal Western Hemlock Zone, $\mathrm{xm2}$ variant, 01 site series
}

\author{
by Gord Nigh ${ }^{1}$
}

\begin{abstract}
The Site Index - Biogeoclimatic Ecosystem Classification (SIBEC) model predicts site index from species and biogeoclimatic site series. The purpose of this project was, for Douglas-fir (Pseudotsuga menziesii [Mirb.] Franco var. menziesii) in the CWHxm2/01 site series, to: 1) verify that the current SIBEC site index estimate of $32.90 \mathrm{~m}$ is accurate, 2) create a more site-specific SIBEC model by including additional variables in the model to capture within-site series variation, and 3) compare the SIBEC site index estimates and their variability when the estimates are obtained using stem analysis data versus data from Bruce's (1981) height-age model. The data set consisted of 40 Douglas-fir plots established in the CWHxm2/01 site series. The analysis shows that the current SIBEC site index estimate should be changed to $34.68 \mathrm{~m}$. No relationship was found between site index and ecological variables within this site series, hence the model could not be made more site-specific. The BEC system aggregates sites into relatively homogeneous units with respect to productivity. The comparison of the SIBEC site index estimates and their variances when estimated using stem analysis and a height-age model were not statistically different. Obtaining a site index estimate from Bruce's model is as accurate as obtaining a site index estimate from stem analysis when the Douglas-fir sample trees are between 50 and 80 years of age.
\end{abstract}

Key words: Biogeoclimatic Ecosystem Classification, Douglas-fir, model error, site index, site series, stem analysis

\section{RÉSUMÉ}

Le modèle tiré de l'Indice de station - Classification biogéoclimatique des écosystèmes (SIBEC) permet de prédire l'indice de qualité d'une station à partir d'une espèce et d'une strate biogéoclimatique. L’objectif de ce projet était, dans le cas du sapin de Douglas (Pseudotsuga menziesii [Mirb.] Franco var. menziesii) retrouvé dans la strate CWHxm2/01 de : 1) vérifier que l'estimé de l'indice de station actuel SIBEC de 32,90 m est exact, 2) créer un modèle SIBEC plus spécifique à la station en ajoutant des variables supplémentaires dans le modèle pour saisir la variation retrouvée au sein d'une strate, 3) comparer les estimés de l'indice de station SIBEC et leur variabilité lorsque les estimés sont obtenus par des données détude de tiges plutôt que par le modèle hauteur-âge de Bruce (1981). Les données portaient sur 40 parcelles de sapin de Douglas établies dans la strate CWHxm2/01. L'étude de ces données indique que l'indice de station SIBEC actuel devrait être porté à 34,68 m. Aucune relation n’a été établie entre l'indice de station et les variables écologiques de cette strate, faisant en sorte que le modèle ne pouvait être transformé pour être plus spécifique à la station. Le système BEC regroupe les stations dans des unités relativement homogènes en termes de productivité. La comparaison entre les estimés de l'indice de station SIBEC et leurs variances obtenus par l'étude des tiges et par le modèle hauteur-âge náffichait pas de différence statistique. L’obtention d'un estimé de l'indice d'une station à partir du modèle de Bruce est aussi précise que lobtention d'un estimé de l'indice d'une station au moyen de létude de tiges dans le cas où les arbres échantillons de sapin de Douglas sont âgés entre 50 et 80 ans.

Mots clés : Classification biogéoclimatique des écosystèmes, sapin de Douglas, erreur du modèle, indice de station, strate biogéoclimatique, étude des tiges

\footnotetext{
${ }^{1}$ Research Branch, British Columbia Ministry of Forests and Range, P.O. Box 9519, Stn. Prov. Govt., Victoria, British Columbia V8W 9C2. E-mail: Gordon.Nigh@gov.bc.ca
} 


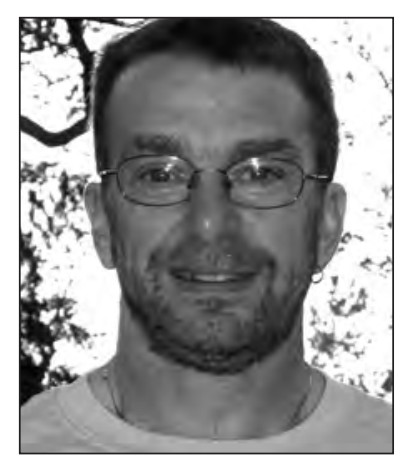

Gord Nigh

\section{Introduction}

Foresters in British Columbia, Canada, use site index, defined as the height of a site tree at breast height age 50 (British Columbia Ministry of Forests 2000), as a measure of site productivity. A site tree is the largest-diameter tree of the target species in a 0.01 -ha plot. The site tree must be dominant or co-dominant and not have non-site factors affecting its height growth above breast height. These conditions provide some assurance that the site tree reflects the productivity of the site (Stearns-Smith 2001). Site index is commonly used in growth and yield models along with other parameters to estimate stand volume (StearnsSmith 2001, Skovsgaard and Vanclay 2008). Stand volume estimates are important in silviculture planning and are a key component of a timber supply analysis and consequently are influential in the determination of an allowable annual cut.

The Biogeoclimatic Ecosystem Classification (BEC) system in British Columbia is used to ecologically classify sites into relatively homogeneous units (MacKinnon et al. 1992, Steen and Coupé 1997). BEC zones are broad areas based on similar climatic conditions. Within the zones are subzones, which are differentiated based on relative precipitation and temperature or continentality. Variants further sub-divide subzones based on their location or distribution within the subzone. At the site level, the site series includes all sites within a subzone variant that are capable of producing the same climax vegetation. Site series are largely determined by the soil moisture and nutrient regimes. Hence, it is expected that there will be differences in productivity across site series (Banner et al. 1993: 7·16).

The Site Index - Biogeoclimatic Ecosystem Classification (SIBEC) model (Ministry of Forests and Range 2008) is an important tool for estimating site index in British Columbia. Work on this model has been ongoing for 15 years (Mah and Nigh 2003). The SIBEC model is developed by first establishing plots in the target site series that have a site tree of the target species. The site tree is used to obtain an estimate of the site index, either through stem analysis or more commonly by taking the breast height age and total height of the site tree and using a model to estimate the site index. The SIBEC model is a look-up table of site index estimates using site series and species as entries into the table. The site index estimates are simply the means of the site index observations for the target species and site series. The mean, sample size, and standard error of the mean are reported in the SIBEC model. A mean site index estimate must be based on a minimum of seven plots before being reported in the second approximation SIBEC model (Ministry of Forests and Range 2008). This is a small sample size but considering that there are over approximately 1000 forested site series in British Columbia that might support three or more species on average, the data collection requirements would be prohibitive if, say, 30 samples per species and site series were required before reporting the estimate. Note, however, that additional sampling above the minimum seven plots is strongly encouraged, especially for common and important site series and species. As a consequence of the data requirements, there are still some species and site series combinations without a site index estimate, particularly second approximation estimates that require more data (Mah and Nigh 2003).

Where site index estimates exist, one of the strengths of the SIBEC model is that site index can be obtained from site series and species; no tree measurements are required. Other models that estimate site index, such as site index, height-age, and growth intercept models, cannot be used unless data are available from suitable site trees on the site (Monserud 1988). Often, it can be difficult to find suitable site trees because the criteria for site trees are rigorous (Monserud 1988). Additionally, if the models are based on breast height age, the site trees may be too young, i.e., below breast height, or the models may lack sufficient accuracy for older stands. The SIBEC model avoids these problems, making it very versatile.

The site index for a single site from a given site series will be different from the estimated mean site index for that site series, i.e., the SIBEC site index estimate. This difference is the error in the site index estimate and it can be large when the variance of the site indexes for a site series is large. A scan of existing data shows that Douglas-fir (Pseudotsuga menziesii [Mirb.] Franco var. menziesii) site indexes range from $15.2 \mathrm{~m}$ to $45.7 \mathrm{~m}$ over all site types. The range in site index for the Western Very Dry Maritime Coastal Western Hemlock subzone variant site series 01 (CWHxm2/01) observed in this study (28.60 $\mathrm{m}$ to $42.64 \mathrm{~m}$, see Results section) is narrower than the range for the whole population of Douglas-fir. Assuming a mean site index for the site series of $34.68 \mathrm{~m}$ (see Results), it is possible to have an 8-m error in estimated site index on a site-specific basis. Additional sampling will tend to reduce the standard error of the mean, but will not lower the error in the SIBEC site index estimate on a site-specific basis because the within-site series variation is not being captured by the SIBEC model. To reduce the site-specific error, the SIBEC model must be modified to include other factors that are important in predicting site index for that site. For example, there is some evidence that site index decreases as elevation increases (Tyler et al. 1995, Fontes et al. 2003, Wang et al. 2004). If this is the case, then including elevation in the SIBEC model would make the site index estimate site-specific and reduce the error in the site index estimate. For timber supply purposes, an accurate overall mean site index is most important since forest inventory polygons are aggregated and averaged. However, for applications such as silviculture planning, foresters will be particularly interested in having more sitespecific site index estimates. This will assist them in applying the correct silviculture operations to the sites and, consequently, allocate silviculture funds more efficiently.

The goal of this research was to develop a more accurate SIBEC model using Douglas-fir in the CWHxm2/01 site series as a pilot. Fig. 1 shows the extent of this subzone variant. Three objectives were set out to achieve this goal:

1. Collect data to confirm that the existing site index estimate for Douglas-fir in the CWHxm/01 $(32.9 \mathrm{~m})$ is adequate for use in the CWHxm 2 and use the new data to improve the SIBEC estimate.

2. Examine which ecological variables can be used to modify the SIBEC model for Douglas-fir in the CWHxm2/01 to provide more site-specific estimates of site index. 


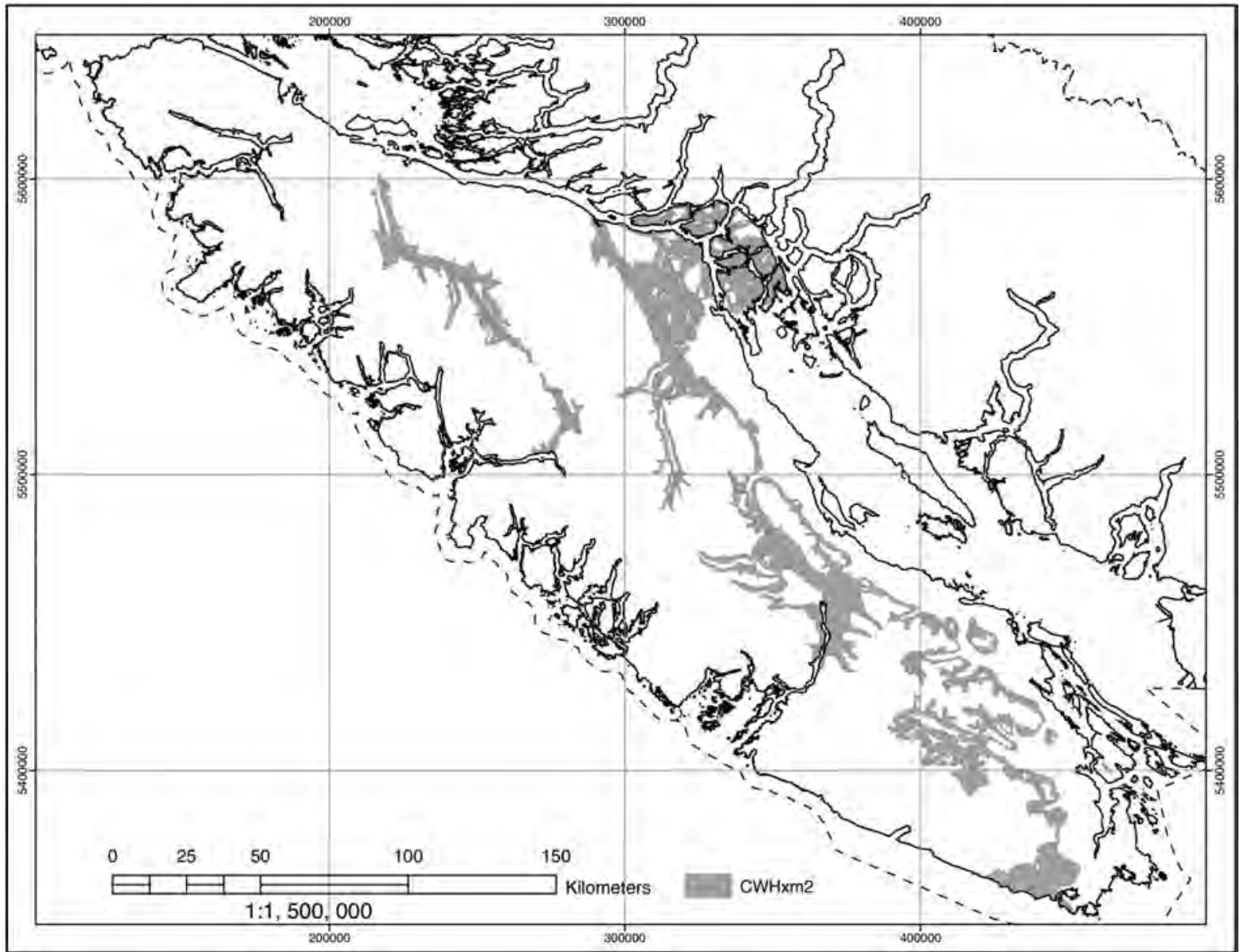

Fig. 1. Map showing the extent of the CWHxm2 subzone variant.

3. Compare the means and variances of SIBEC site index estimates for Douglas-fir in the CWHxm2/01 that were developed with site index data from stem analysis and estimated from Bruce's (1981) height-age model.

\section{Methods}

\section{Data collection}

The target species for this project is coastal Douglas-fir in the CWHxm2/01 site series. This species and site were chosen because Douglas-fir is common in this site series, potential samples should be plentiful, and there is good access to the sites. The sample size was targeted at 50 but was eventually limited by the project budget.

Thirty-five stem analysis plots were established within the available budget. The characteristics that were sought for the sample site and the Douglas-fir site tree during plot establishment are found in the SIBEC Sampling and Data Standards (http://www.for.gov.bc.ca/hre/sibec/documents/standards.pd f). The site tree in each 0.01 -hectare stem analysis plot was felled and split longitudinally. The annual pith nodes were identified and their heights were recorded. In accordance with the definition of site index, the height of the $50^{\text {th }}$ node above breast height $(1.3 \mathrm{~m})$ was the observed site index. The height and node count above breast height (i.e., the breast height age) of the highest node identified were also recorded. This was not always the top of the tree because top damage sustained while felling prevented the splitting of the stem to the top without undue difficulty. The height of the highest identified node was used in the analysis of the error in the site index estimates. This objective was considered to be a minor component of the project; hence, an unwarranted amount of time was not expended in reconstructing the tree when severe breakage occurred. A full ecosystem classification (Luttmerding et al. 1990) was done on the 10 -m radius ecosystem plot, which was centred on the site index plot.

The 35 plots were supplemented with five plots from the CWHxm2/01 site series that were available from a Douglasfir growth intercept project (Nigh 1996). The two projects were similar in the way the data were collected. However, the supplemental dataset had less extensive ecosystem data, the plots were larger $\left(400 \mathrm{~m}^{2}\right)$, and three site trees per plot were sampled. One site tree per plot was randomly selected for the analysis. The difference in plot size and number of trees per plot is due to changing standards for this type of work. 


\section{Data analysis}

All data analyses were performed using the statistical language R (R Development Core Team 2008). Aspect was transformed so that it was between 0 and 2 (Beers et al. 1966) to account for sites with southerly aspects being drier and hotter, and consequently having lower productivity. The transformed aspect takes its minimum and maximum values when the original aspect is $225^{\circ}$ and $45^{\circ}$, respectively, where $0^{\circ}$ is north.

The first objective was met by calculating the mean site index, comparing it to the existing site index estimate for the CWHxm2/01 site series, and reconciling the differences.

To meet the second objective, correlations between the ecological variables and site index were sought. Site-specific estimates of site index can be obtained by determining which variables are related to site index within the CWHxm2/01 site series and including these variables in the SIBEC model. The ecological variables used to further refine the SIBEC model were chosen a priori in consultation with the provincial ecologist (Will MacKenzie, personal communication) as factors that should affect site productivity. Table 1 lists these variables. Selecting variables in advance allows specific hypotheses to be tested without affecting $\mathrm{p}$-values (Stauffer 2008) and avoids the problem of picking up spurious relationships (Sen and Srivastava 1990). Scatter plots of site index versus the ecological variables were created to screen for potential relationships and for possible transformations of the ecological variables. Predictor (ecological) variables were included in a linear regression model (for continuous variables) or an ANOVA model (for class variables) singly and using all possible pairs to determine which variables were significant predictors of site index. No attempt was made to include more than two variables in the SIBEC model because there were no significant two-variable models.
The third objective was met by comparing a SIBEC model developed with data obtained from two different methods of determining site index: observing it from stem analysis or estimating it with Bruce's (1981) height-age model using the height and breast height age of the tree at the greatest age recorded as predictor variables. The mean, variance, and standard error of the mean site index for both methods of determining site index were calculated. The mean difference in the site indexes was also calculated. These differences were compared using a paired t-test under the null hypothesis that the model is unbiased, i.e., the mean difference in site index is zero. The variances of the two site index estimates were also compared using an F-test (Mason et al. 1989) under the null hypothesis that the two methods of determining site index are equally precise, i.e., the ratio of the two variances is one. The observed and estimated site indexes were plotted to confirm that the site indexes shared a common trend.

\section{Results}

The site index estimate in the current SIBEC model for Douglas-fir in the CWHxm/01 is $32.9 \mathrm{~m}$ with a standard error of $1.4 \mathrm{~m}$ (Ministry of Forests and Range 2008), based on 13 samples. This is different from the mean site index of $34.68 \mathrm{~m}$ (range: $28.60 \mathrm{~m}$ to $42.64 \mathrm{~m}$ ) found in this study, which is based on 40 samples.

The scatter plots did not reveal any relationship between site index and the ecological variables under consideration, nor did they indicate that any transformations of the ecological variables were needed. The statistical analysis did not reveal any significant relationships between site index and the ecological variables in either the one or two variables models (Table 1, p-values from the F-test for the significance of the analysis of single-variable models are shown in this table and they ranged from 0.1115 to 0.8975 ).

Table 1. Explanatory variables used in the analysis to reduce the error in the SIBEC model. The p-value is the significance of the F-test for the model. The observed values give some indication of the distribution of the observations. The lower and upper ends of the ranges presented in this table represent the range of the variables observed in this study.

\begin{tabular}{|c|c|c|c|c|}
\hline $\begin{array}{l}\text { Variable } \\
\text { name }\end{array}$ & $\begin{array}{l}\text { ontinuous (C) / } \\
\text { discrete (D) }\end{array}$ & Description & Observed values (\# of plots) & p-value \\
\hline UTMN & $\mathrm{C}$ & UTM northing (m) & $\begin{array}{l}5360353-5400000(5), 5400001-5500000(15) \\
5500001-5577369(20)\end{array}$ & 0.8975 \\
\hline UTME & $\mathrm{C}$ & UTM easting (m) & $\begin{array}{l}295560-300000(1), 300001-400000(28) \\
400001-438862(9), \text { unknown (2) }\end{array}$ & 0.6908 \\
\hline SMR & $\mathrm{D}$ & Soil moisture regime & Slightly dry (28), fresh (12) & 0.1369 \\
\hline SNR & $\mathrm{D}$ & Soil nutrient regime & Poor (4), medium (36) & 0.1115 \\
\hline Elev & $\mathrm{C}$ & Elevation (m) & 69-100 (3), 101-200 (20), 200-300 (12), 300-340 (5) & 0.3073 \\
\hline Slope & $\mathrm{C}$ & Slope $(\%)$ & $0-10(14), 11-20(15), 21-30(7), 31-40(3), 41-44(1)$ & 0.8279 \\
\hline Aspect & $\mathrm{C}$ & Degrees & $1-90$ (11), 91-180 (4), 181-270 (16), 271-360 (6), unclassified (3) & 0.4537 \\
\hline SlopePos & $\mathrm{D}$ & Slope position & Upper (2), mid (28), lower (6), toe (1), level (3) & 0.3951 \\
\hline HumusForm & $\mathrm{D}$ & Humus form & Mor (24), mormoder (15), mull (1) & 0.5791 \\
\hline RootZonePartSize & $\mathrm{D}$ & $\begin{array}{l}\text { Rooting zone } \\
\text { particle size }\end{array}$ & $\begin{array}{l}\text { Coarse-loamy (5), coarse-loamy-skeletal (9), fine-loamy (6), } \\
\text { fine-loamy-skeletal (4), sandy (1), sandy-skeletal (6), } \\
\text { unclassified (9) }\end{array}$ & 0.1606 \\
\hline Drainage & $\mathrm{D}$ & Drainage & Well (31), moderately-well (4), unclassified (5) & 0.8666 \\
\hline
\end{tabular}


The mean and variance of the stem analysis-based site indexes and the estimated site indexes are $34.68 \mathrm{~m}$ and 10.02 , and $34.80 \mathrm{~m}$ and 9.28 , respectively. The plot of estimated versus observed site index showed that the estimated site index increased as the observed site index increased. The average difference between the two site indexes is $0.12 \mathrm{~m}$ with a standard error of 0.14 . This difference is not statistically significantly different from $0(p=0.38)$. The ratio of the two variances is 1.08 . This ratio is not significantly different from $1(\mathrm{p}$ $=0.81$. .

\section{Discussion}

The current SIBEC model does not distinguish between the two variants of the CWHxm subzone (the $\mathrm{xm} 1$ and $\mathrm{xm} 2$ ) and cites a site index of $32.9 \mathrm{~m}$ for Douglas-fir in the 01 site series, averaged over both variants. The $\mathrm{xm} 1$ and $\mathrm{xm} 2$ are often not differentiated because of their similarity in properties and management implications (Green and Klinka 1994). Based on the UTM coordinates of the 13 plots in the SIBEC data warehouse, it was possible to determine which plots were in the $\mathrm{xm} 1$ and the $\mathrm{xm} 2$ variants. The mean site index of the eight plots in the xm1 variant was $31.2 \mathrm{~m}$ with a standard error of $1.8 \mathrm{~m}$, and the mean site index of the five plots in the $\mathrm{xm} 2$ was $35.5 \mathrm{~m}$ with a standard error of $2.0 \mathrm{~m}$, which is closer to the mean site index of $34.68 \mathrm{~m}$ found in this study than the $32.9 \mathrm{~m}$ from the current SIBEC model. When examined by variant, the results of this study support the data in the SIBEC data warehouse for the xm2, noting however, that the five plots from the existing SIBEC data warehouse were also used in this study. Perhaps more importantly, these results show a need to distinguish between the two variants for growth and yield applications.
This research found that the predicted site index from the SIBEC model for Douglas-fir in the 01 sites series within the CWHxm2 variant cannot be made more site-specific by incorporating other ecological variables that are commonly collected during an ecosystem assessment into the model. The BEC system groups sites into site series, which have the same or equivalent environmental properties and potential seral vegetation (Meidinger and Pojar 1991). The success of this grouping is apparent in the data collected in this project, as evidenced by the small ranges in many of the variables (Table 1). For example, the range of soil moisture regime and soil nutrient regime is small, with most sites being in one moisture or nutrient class. The manifestation of this homogeneity is consistency and closeness of the height trajectories for Douglas-fir height growth in the CWHxm2/01 site series (Fig. 2) and the compact distribution of site index (Fig. 3). This homogeneity within the site series has likely led to the inability to find correlations between site index and ecological variables. Elevation may be an important predictor of site index only at higher elevations. A larger sample size may also be necessary to draw out less obvious relationships. It is important to note that these results do not mean that the ecological variables that were examined do not, in general, have any effect on site productivity. When examined across a wider ecological amplitude, other research has shown that these ecological variables do influence site productivity.

Incorporating additional ecological variables into the SIBEC model to make it more site-specific would increase the complexity of the model. However, the increased complexity may lead to difficulties in the application of the model. For example, a common application is to assign site indexes to forest stands in a management unit by linking site index esti-

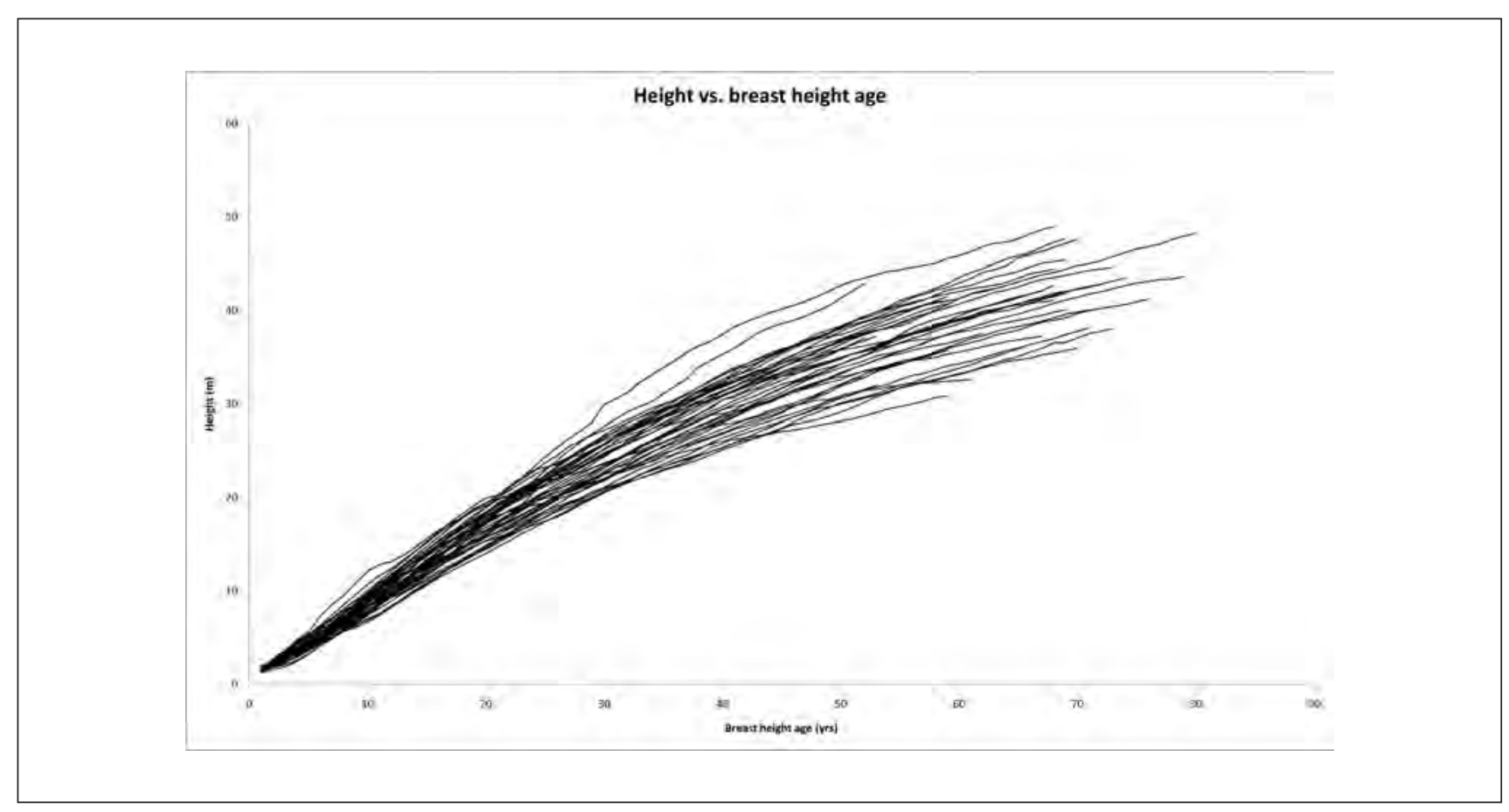

Fig. 2. Height trajectories for the 40 Douglas-fir site index plots. 


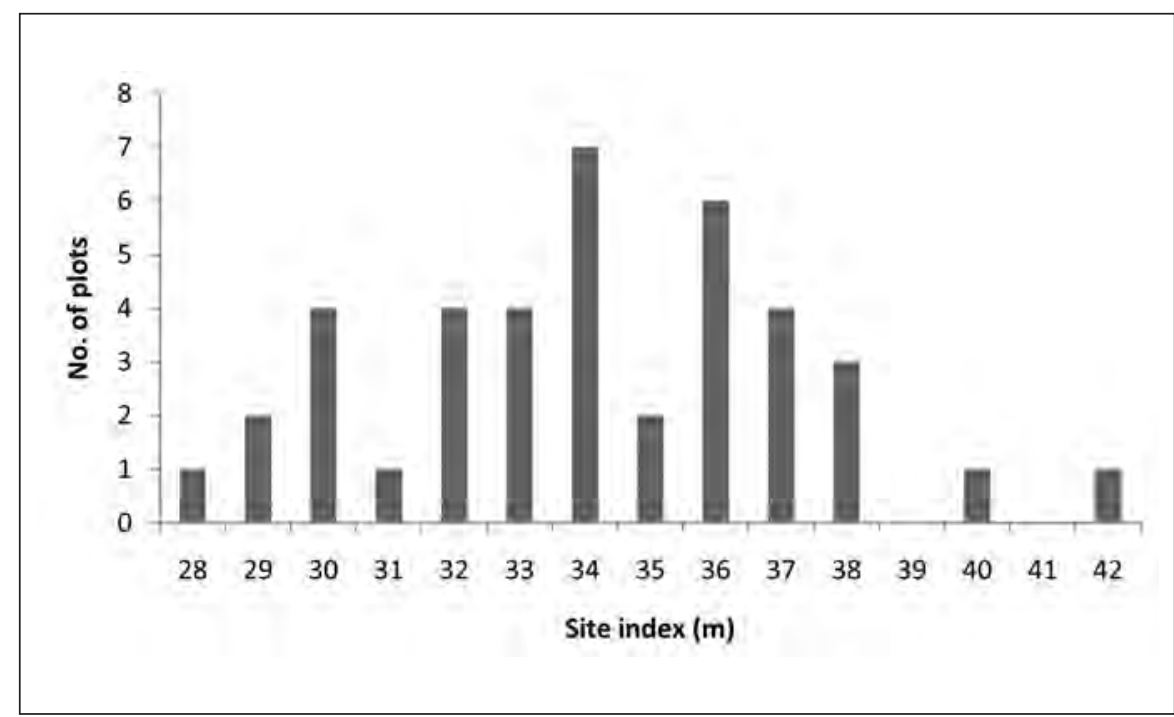

Fig. 3. Histogram of the site indexes of the 40 Douglas-fir site index plots.
1. The SIBEC estimates of site index obtained from Bruce's model would also be biased, perhaps to the point of being unusable. These site index estimates would then have to be adjusted through some rigorous procedure or they would have to be replaced with estimates based only on stem analysis data, which would be costly and time-consuming. Alternatively, a new model could be developed to estimate site index for Douglas-fir which, again, is a significant undertaking.

2. When developing the SIBEC model, additional samples would have to be taken get a better estimate of the mean site index.

Bruce's (1981) model is sufficiently mates from SIBEC with a Predictive Ecosystem Map (PEM; Olivotto and Meidinger 2001). This is particularly useful for timber supply analyses (Olivotto and Meidinger 2001). A PEM may only have a limited number of variables besides site series that can be used to make site index predictions (Jones and Meidinger 2000). Therefore, a more complex SIBEC model that includes other ecological variables could render the model unusable when coupled with a PEM if a predictor variable is not available from the PEM.

The lack of correlations between ecological variables and site index within the CWHxm2/01 site series means that more site-specific site index information cannot be obtained from the SIBEC model for this site series. Other methods of estimating site index are available, such as the growth intercept method or using historical information. The preferred method of estimating site index should be based on the relative accuracy of the available tools and the availability of the data needed to use the tools. Therefore, in some (perhaps many) instances, the SIBEC model will be the best choice for making silviculture decisions. As noted previously, there is potential for significant errors in the SIBEC model. Decisions based on SIBEC site index estimates should be evaluated and possibly changed as stands grow and better site index information becomes available.

The analysis to examine the mean and variance of the two methods of obtaining site index estimates for SIBEC revealed some positive results. The model-based site index estimates were not significantly different from the stem analysis-based site indexes and both methods of estimating site index were equally precise. In essence, this part of the project was a small validation exercise for the Bruce (1981) height-age model (Newberry and Stage 1988), at least over the age range of the data that were analyzed. The breast height age of the trees in this study ranged from 51 to 80 years. This study suggests that this would be a good age range to target for future sampling of Douglas-fir site index when the Bruce (1981) height-age model is used to estimate site index. If the validation had shown that the Bruce model was either biased or had poor precision for estimating site index, then these findings would have had at least two consequences: accurate that neither of these consequences will be realized.

\section{Conclusion}

The existing site index estimate for the CWHxm/01 site series differs from that for the CWHxm2/01 site series found in this study. Better growth and yield information can be obtained by using the site index estimate that is specific to the $\mathrm{xm} 2 \mathrm{sub}$ zone variant.

The BEC system adequately aggregates sites into units that are homogeneous with respect to site productivity for Douglas-fir in the CWHxm2/01 site series. The SIBEC model cannot be modified to give more site-specific estimates of site index. However, repeating this experiment with a larger sample size may find some variables that can be used to make the SIBEC model more site-specific.

The site index estimates from the Bruce (1981) height-age model are as accurate as the site index estimates obtained from stem analysis for trees between 50 and 80 years of age.

\section{Acknowledgments}

I thank Will MacKenzie, B.C. Ministry of Forests and Range, for helping identify which ecological variables might influence site productivity. Huapeng Cheng, B.C. Ministry of Forests and Range, produced the map for me. Thanks to Shirley Mah, Peter Ott, and Al Powelson, all with the B.C. Ministry of Forests and Range, for valuable review comments. Two anonymous reviewers provided excellent suggestions that greatly improved the manuscript. FIA-FSP provided the funding for this project.

\section{References}

Banner, A. W. Mackenzie, S. Haeussler, S. Thomson, J. Pojar and R. Trowbridge. 1993. A field guide to site identification and interpretation for the Prince Rupert Forest Region. B.C. Min. For., Victoria, B.C. Land Manage. Handb. No. 26. Available at http:// www.for.gov.bc.ca/hfd/pubs/docs/lmh/lmh26.htm.

Beers, T.W., P.E. Dress and L.C. Wensel. 1966. Aspect transformation in site productivity research. J. For. 64: 691-692.

British Columbia Ministry of Forests. 2000. A method to check the performance of a growth intercept model. B.C. Min. For., For. Pract. 
Br., Victoria, B.C. Silv. Note 24. Available at http://www.for. gov.bc.ca/hfp/publications/00125/SN24.pdf [accessed December 1, 2009].

Bruce, D. 1981. Consistent height-growth and growth-rate estimates for remeasured plots. For. Sci. 27: 711-725.

Fontes, L., M. Tome, F. Thompson, A. Yeomans, J.S. Luis and P. Savill. 2003. Modelling the Douglas-fir (Pseudotsuga menziesii (Mirb.) Franco) site index from site factors in Portugal. For. 76: 491-507.

Green, R.N. and K. Klinka. 1994. A field guide to site identification and interpretation for the Vancouver Forest Region. B.C. Min. For., Victoria, BC. Land Manage. Handb. No. 28.

Jones, C. and D. Meidinger. 2000. Introduction to attribute selection in PEM [online]. EcoNote2000-3. Available at www.for.gov. bc.ca/hre/ecogen/downloads/econt03.pdf [accessed January 2010].

Luttmerding, H. A., D. A. Demarchi, E. C. Lea, D. V. Meidinger and T. Vold. 1990. Describing ecosystems in the field. Min. Env. Lands Parks, Victoria, BC. MOE Manual 11.

MacKinnon, A., D. Meidinger and K. Klinka. 1992. Use of the biogeoclimatic ecosystem classification system in British Columbia. For. Chron. 68: 100-120.

Mah, S. and G.D. Nigh. 2003. SIBEC site index estimates in support of forest management in British Columbia. Res. Br., B.C. Min. For., Victoria, BC. Tech. Rep. 004. Available at www.for.gov.bc.ca/hfd/ pubs/docs/tr/tr004.htm.

Mason, R.L., R.F. Gunst and J.L. Hess. 1989. Statistical design and analysis of experiments with applications to engineering and science. John Wiley \& Sons, Toronto, ON.

Meidinger, D. and J. Pojar. 1991. Ecosystems of British Columbia. B.C. Min. For., Res. Br., Victoria, BC. Spec. Rep. Ser. No. 6.

Ministry of Forests and Range. 2008. Site index estimates by site series (SIBEC) - second approximation [online]. Available at http://www.for.gov.bc.ca/hre/sibec/ [accessed October 2009].

Monserud, R.A. 1988. Variations on a theme of site index. In Forest Growth Modelling and Prediction. pp. 419-427. USDA For. Serv. Gen. Tech. Rep. NC-120.
Newberry, J.D. and A.R. Stage. 1988. Validating forest growth models: procedures defined by resource decision. In Forest Growth Modelling and Prediction. pp. 786-793. USDA For. Serv. Gen. Tech. Rep. NC-120.

Nigh, G.D. 1996. A growth intercept model for coastal Douglas-fir. B.C. Min. For., Victoria, BC. Res. Rep. 10.

Olivotto, G. and D. Meidinger. 2001. Development of EcoYield - a conceptual model for timber supply analysis using predictive ecosystem mapping and site index-ecosystem relationships [online]. EcoNote2001-1. Available at www.for.gov.bc.ca/hre/ecogen/downloads/EcoNote2001-1.pdf [accessed November 2009].

R Development Core Team. 2008. R: A language and environment for statistical computing. R Foundation for Statistical Computing, Vienna. ISBN 3-900051-07-0. Available at http://www.R-project.org. Sen, A. and M. Srivastava. 1990. Regression analysis theory, methods, and applications. Springer Verlag, New York.

Skovsgaard, J.P. and J.K. Vanclay. 2008. Forest site productivity: a review of the evolution of dendrometric concepts for even-aged stands. For. 81: 13-31.

Stauffer, H.B. 2008. Contemporary Bayesian and frequentist statistical research methods for natural resource scientists. John Wiley \& Sons, Hoboken, NJ.

Stearns-Smith, S. 2001. Making sense of site index estimates in British Columbia: a quick look at the big picture [online]. B.C. J. Ecosys. Manage. 1: 1-4. Available at www.forrex.org/JEM/ISS14/ vol1_no2_art6.pdf [accessed January 2010].

Steen, O.A. and R.A. Coupé. 1997. A field guide to forest site identification and interpretation for the Cariboo Forest Region. B.C. Min. For., Victoria, BC. Land Manage. Handb. No. 39.

Tyler, A.L., D.C. Macmillan and J. Dutch. 1995. Predicting the yield of Douglas-fir from site factors on better quality sites in Scotland. Ann. Sci. For. 52: 619-634.

Wang, G.G., S. Huang, R. Monserud and R. Klos. 2004. Lodgepole pine site index in relation to synoptic measures of climate, soil moisture and soil nutrients. For. Chron. 80: 678-686. 